\title{
Multilevel modelling of factors associated with caesarean section in Ethiopia: community based cross sectional study
}

\author{
Abebaw Gedef Azene ${ }^{1 *}$, Abiba Mihret Aragaw ${ }^{2}$ and Mihretie Gedefaw Birlie ${ }^{3}$
}

\begin{abstract}
Objective: The aim of this study was to identify socio-demographic and health related factors associated with caesarean section in Ethiopia.

Results: A total of 256 mothers undergoing to CS among 7193 delivery. Average maternal age of a participant was 29.26 years and $80 \%$ of mothers having two and more children. A woman delivered in private institution was 30\% $(A O R=1.29 ; 95 \% \mathrm{Cl} 1.25,1.32)$ more likely undergoing $C S$ as compared to home delivery. Factors associated with CS were higher education level $(A O R=1.09,95 \% \mathrm{Cl} 1.07,1.12)$, preceding birth interval $(A O R=1.01 ; 95 \% \mathrm{Cl} 1.00 .1 .03)$, multiple pregnancy $(A O R=1.11 ; 95 \% \mathrm{Cl} 1.08,1.15)$, multiple parity $(A O R=0.98 ; 95 \% \mathrm{Cl} 0.97,0.99)$, large size the child $(A O R=1.01 ; 95 \% \mathrm{Cl} 1.001,1.02)$, richest households $(A O R=0.98 ; 95 \% \mathrm{Cl} 0.97,0.99)$, rural residence $(A O R=0.9895 \% \mathrm{Cl}$ $0.96,0.99)$ and Addis Ababa (AOR $=1.06 ; 95 \% \mathrm{Cl} 1.04,1.09)$. As a conclusion and recommendation, the prevalence of CS higher in private institutions and Addis Ababa, so professionals should apply CS alone medical indication.
\end{abstract}

Keywords: Caesarean section, Multilevel modelling, Prevalence, Ethiopia

\section{Introduction}

Caesarean section is an operative technique to deliver a fetus from mothers through abdominal and uterine surgery $[1,2]$. Caesarean section has more preferring by mothers in the world $[3,4]$. WHO reported that the prevalence of CS were $18.6 \%$ worldwide, $7.3 \%$ in Africa and small in sub-Shara Africa [5, 6]. In Nigeria, the prevalence of CS was $2.1 \%$ [7]. The prevalence of CS varies from $2 \%$ up to $64 \%$ in Ethiopia $[8,9]$. The trend is increasing in Ethiopia [3, 10].

Obstetric care services is improved in the country [11, 12]. Due to this, CS have been performed either by the mothers' preference or the professional business based recommendation [13-15]. However, Unnecessary CS increases risks on both maternal outcomes and babies $[16,17]$. The risks were postpartum morbidity, reduced morbidity, infection, respiratory problem on chilled, less

\footnotetext{
*Correspondence: abebaw2516@gmail.com

1 Department of Epidemiology and Biostatistics, Bahir Dar University, Bahir Dar, Ethiopia

Full list of author information is available at the end of the article
}

breastfeeding and birth trauma despite of the fact that the prevalence of CS is increasing $[18,19]$.

Due to the fact that maternal age during delivery, place of delivery, residence, maternal education, ANC, parity, size of the child and multiple pregnancy were factors associated with CS $[7,20]$.

Studies have been focused on medical indicators of CS. Besides medical indicators, sociodemographic, health factors having a contribution to increase the prevalence of CS in Ethiopia. Therefore; this study intended to assess associated socio-demographic, health factors of CS. This research will be vital to provide some input for health institution.

\section{Main text \\ Methods \\ Study design and setting}

Community based cross-sectional study was conducted using 2016 EDHS data collected from January 18 to June 27, 2016. 7,193 women were included for the study. The dataset has a hierarchical structure as a woman nested within geographic regions and residence. The hierarchy 
for this study follows individuals as level-1, regions and residence as level-2.

\section{Inclusion and exclusion criteria}

All women (age 15-49) who give birth within five years prior to the study were considered during the 2016 EDHS survey was included.

\section{Dependent variable}

The outcome variable was a mode of delivery classified as either vaginal delivery $(=0)$ or CS delivery $(=1)$.

\section{Independent variable}

Explanatory variables were classified level-1 and level-2 factors. Level-1 factors were a religion, maternal education, household wealth index, place of delivery, parity, birth order, preceding birth interval, the history of abortion, ANC, anaemic status, multiple pregnancy, drug takes for intestinal disease, sex of the child and size of the child. Level-2 factors were region and residence.

\section{Statistical analysis and model}

Bivariable analysis was applied to examine the association between each variable and CS. Multilevel logistic regression model was used to comprehend community variation (level-2) and identifying socio-demographic health (level-1) factors associated with CS.

\section{Results}

A total of 7193 mothers were eligible. Out of those mothers, 256 (1.9\% weighted by region) were undergoing CS. Average maternal age was 29.26 years, $80 \%$ of mothers having more than one children, $8.85 \%$ mothers had a history of abortion. Of mothers had a history of abortion, $4.87 \%$ were undergoing to CS.

Among mothers undergoing to CS, $54.29 \%$ were orthodox, $33.20 \%$ were primary school educated, $12.11 \%$ had a history of abortion, $9.37 \%$ had taken the drug for intestinal disease during pregnancy and $93.75 \%$ had multiple pregnancy (see Tables 2 and 3 in Appendix). Regarding level-2 factors, $21.9 \%$ were residing in Addis Abeba. $12.7 \%$ residing from urban areas (see Table 1 ).

Among 6937 vaginal delivered mothers, 4317 (62.23\%), $2411(34.76 \%)$ and 6331 (91.26\%) weren't educated, from poorest household and hadn't history of abortion, respectively.

Bivariate analysis of factors associated with CS were conducted. See Table 2 in Appendix and Table 1.

\section{Multivarable multilevel logistic regression analysis of CS}

Measure of association and random intercepts for CS are presented Table 3 in Appendix. The results of the empty model (Model_1) indicated that there was a significant
Table 1 Bivariate analysis of association between community level factors with CS, EDHS 2016

\begin{tabular}{lccc}
\hline Covariates & CS n (\%) & All vaginal births n (\%) & P-value \\
\hline Region & & & $<0.0001$ \\
Tigray & $21(2.7)$ & $751(97.3)$ & \\
Afar & $6(0.9)$ & $641(99.1)$ & \\
Amhara & $16(2.1)$ & $748(97.9)$ & \\
Oromia & $14(1.4)$ & $1017(98.6)$ & \\
Somali & $5(0.6)$ & $801(99.4)$ & \\
Benshangul & $6(1)$ & $570(99.0)$ & \\
SNNP & $23(2.6)$ & $870(97.4)$ & \\
Gambella & $6(1.1)$ & $528(98.9)$ & \\
Harari & $46(11.2)$ & $365(88.8)$ & \\
Addis Abeba & $82(21.9)$ & $293(78.1)$ & \\
Dire Dewa & $31(8.1)$ & $353(91.9)$ & \\
Residence & & & \\
Urban & $192(75)$ & $1320(19.03)$ & \\
Rural & $64(25)$ & $5617(80.97)$ & \\
\hline
\end{tabular}

variation of CS between level-2 factors (random intercept variance $=1.064$, $\mathrm{P}$-value $=0.000$ ).

Similarly, the ICC in the empty model implied that $24.44 \%$ of the total variance in mode of delivery was credited to differences between level-2 factors.

In Model_2 only level-1 variables were added. With this, maternal education, multiple pregnancy, preceding birth interval, place of delivery, size of the child, parity and household wealth index were significantly associated with CS. ICC in Model_2 indicated that, 23.33\% of the variation of CS were accountable to differences across levels- 2 factors. As shown by a PCV, $5.9 \%$ of the variance in CS across the level-2 was explained by level-1 characteristics.

Model_3, only level-2 factors were added. The result revealed that a woman residing in a rural community was significantly associated with CS. In addition to this; a woman from Somali, Gammbella, Harreri, Addis Abeba and Dire Dewa regions were significantly associated with CS. The ICC showed that differences between level-2 factors account $23.98 \%$ of the variation of CS. In addition, PCV indicated that $3.7 \%$ of variation of CS explained by level-2 characteristics.

Model_4, the final model included both level-1 and level-2 factors simultaneously which have a P-value less than 0.1 from bivariable analysis. The estimated ICC, $23.35 \%$ of the variability in CS were accountable to differences between level-2 factors. PCV indicated that, $3.5 \%$ of variation of CS across level-2 explained by both level-1 and level-2 factors. After adjusting the other level-1 and level-2 factors; maternal education, preceding birth interval, place of delivery, multiple pregnancy, size of child, parity and household wealth index in level-1 
and also residence and region (Gambella, Hareri, Addis Abeba and Dire Dewa) in level-2 were significantly associated with CS.

The odds of a mother having higher education, undergoing to CS were $9 \%(\mathrm{AOR}=1.09,95 \%$ CI $1.07,1.12)$ more likely compared to mothers who hadn't educated. The odds of experiencing CS were 1.01 (AOR $=1.01$; $95 \%$ CI 1.00, 1.03) times more likely for one month increases.

Regarding a woman having multiple pregnancy was $11 \%$ $(\mathrm{AOR}=1.11 ; 95 \% \mathrm{CI} 1.08,1.15)$ more likely to give birth by CS. Likewise, a woman in public, private and NGO health institution was 1.04 (AOR =1.04; 95\% CI 1.03, 1.05), 1.29 $(\mathrm{AOR}=1.29 ; 95 \% \mathrm{CI} 1.25,1.32), 1.07(\mathrm{AOR}=1.07 ; 95 \%$ CI 1.02, 1.12),1.09 (AOR $=1.09 ; 95 \%$ CI 1.05, 1.130) times more likely undergoing to CS as compared to home delivery, respectively. A woman having large child size more likely deliver by $\mathrm{CS}$ than medium $(\mathrm{AOR}=1.01 ; 95 \% \mathrm{CI}$ $1.001,1.02)$. A woman having between two and five children was $2 \%(\mathrm{AOR}=0.98$; 95\% CI $0.97,0.99)$ less likely undergoing to CS as compared to having a primary child.

The odds of a woman from the richest households were $2 \%(\mathrm{AOR}=0.98 ; 95 \% \mathrm{CI} 0.97,0.99)$ less likely undergoing to CS as compared to a woman from the poorest households. Similarly a woman in rural residence was $2 \%$ $(\mathrm{AOR}=0.9895 \%$ CI $0.96,0.99)$ less likely to give birth by CS as compared to urban counterparts. Looking Region, a woman residing from Harerri had $2 \%(\mathrm{AOR}=0.98$; $95 \%$ CI $0.96,0.99$ ) less likely undergoing to CS compared with Tigray. The odds of a woman from Gambella, Addis Abeba and Diere Dewa having more likely undergoing to CS than a woman from Tigray (AOR $=1.02$; $95 \%$ CI 1.01,1.04), $(\mathrm{AOR}=1.06 ; 95 \% \mathrm{CI} 1.04,1.09)$ and $\mathrm{AOR}=1.08 ; 95 \% \mathrm{CI}$ $1.06,1.11)$ respectively. See Table 3 in Appendix.

\section{Discussion}

Community based cross-sectional study was conducted using 2016 EDHS data collected from January 18 to June 27,2016 . The aim of the study was to identify associated socio-demographic, health factors of CS.

The findings showed that a woman's having higher educated were more likely undergoing to CS. This could be due to a reason that educated woman search a means to minimize labour and more worry their health. Similar findings were observed a study conducted in Dessie town and Iran $[10,20]$.

CS was significantly associated with proceeding birth interval. A woman having more proceeding interval; more likely undergoing to CS. This finding is also supported by findings from Eastern Ethiopia and Developing countries $[9,21]$. This could be due to a reason relation between the preceding birth interval and uterus.
The other factors associated with CS were multiple pregnancies. A mother faced multiple pregnancy was more likely to deliver by CS compared to single pregnancy. This result agreed with a study conducted in Nigeria and Ethiopia [7, 9]. The possible explanation could be mothers having multiple pregnancies were more sought health institution related with complication of labour.

Place of delivery was significantly associated with CS. A mother delivered in Private, NGO and governmental hospital was more likely undergoing to CS than home delivered woman. Possible explanation could be related with access of CS in health institutions and due to business oriented professional recommendation. This finding also supported a finding from Harerri and Dessie town $[9,10]$. The finding revealed that the size of the child associated with CS. A woman having a large size child more likely delivered by CS. This finding supported a finding in Nigeria and Bahir Dar $[7,22]$. The possible reason could be due to complication of labour and related to the interval of the uterus.

Mothers having two up to five children were less likely undergoing to CS as compared to primary birth. This finding supported a findings conducted in Egypt and Southwest Ethiopia [23, 24]. A possible reason could be related with experience of a uterus and labour of a woman.

Surprisingly, a study revealed that ANC hadn't significant association with CS. This finding consistent with a study conducted in Sodo [25]. The reasons could be seek skilled person if they start ANC earlier.

The findings verified that a woman from the richest household had smaller odds undergoing to CS compared to a woman from poorest household. This finding is supported a study conducted at Addis Abeba and Bangladesh $[11,14]$.This could be due to a reason free service of CS in governmental health institution. In addition to this, mothers from richest household having more access of information from media.

In the study, mothers from rural residence had less likely to deliver by CS than mothers from urban. This finding was agreed a findings conducted in Bangladesh and Nigeria [7, 14]. This could be due to the fact that mothers from rural residence having less chance to access hospitals. In addition to this, most women from a rural residence were poor, both economically and information. But, this finding inconsistent a findings conducted at the Felege Hiwot referral hospital [22, 26].

Similarly, a mother residing from Harerri region were less likely undergoing to CS. However, mothers from Gambella, Addis Abeba, and Diere Dewa were more likely delivered by CS as compared mothers from Tigray region. This findings consistent with the studies conducted in Sodo [25]. This observation may be related to access of health institutions in the region. 


\section{Conclusions}

This Study found that 256 mothers out of 7193 were undergoing CS. Most of mothers undergoing to CS were delivered at government health institutions. Factors associated with CS were maternal education, preceding birth interval, multiple pregnancy, place of delivery, parity, the size of the child and household wealth index at individual characteristic were significantly associated with CS. All community factors (Residence and region) were associated with CS. Therefore, the prevalence of CS was varied based on residence and regions in Ethiopia. As a recommendation, the prevalence of CS high in private institutions and Addis Ababa City, so professionals should apply CS alone medical indication.

\section{Limitation of the study}

The study was used secondary data due to this; a respondent's may answer usually underestimate in sociodemographic factors and overestimate health related factors since the study was retrospective. Primary data is preferable to access obstetric factors. Therefore, the use of this information for comparison and decision-making should consider the inherent limitation of the study.

\section{Abbreviations}

ANC: antenatal care; EDHS: ethiopian demographic health survey; DHS: demographic health survey; CS: caesarean section; EA: enumerate Area; sd: standard deviation.

\section{Acknowledgements}

The authors would like to thank the study participants, data collectors, and CSA for giving the data and their support to finish the study.

\section{Authors' contributions}

AGA was responsible for the study design. AGA and AMA contributed the statistical analyses and interpretation of the results. AGA and MG drafted the manuscript and revised it critically and all authors approved the final version. All authors read and approved the final manuscript.

Funding

Not applicable.

Availability of data and materials

The datasets used and/or analysed during the current study available from the corresponding author and EDHS 2016 on reasonable request.

\section{Ethics approval and consent to participate}

The researcher have taken the data from the Ethiopian demographic, health survey and it was secondary. The researcher conducted this study in accordance with the guidelines laid down in the Declaration of Helsinki and all procedures involving human subjects. During the data collection, the participants were agreeing consent letter. For further information, contact the author.

Consent for publication

Not applicable.

\section{Competing interests}

The author declares that they have no competing interests.

\section{Author details}

${ }^{1}$ Department of Epidemiology and Biostatistics, Bahir Dar University, Bahir Dar, Ethiopia. ${ }^{2}$ Department of Statistics, Debre Markos University, Debre Markos, Ethiopia. ${ }^{3}$ Department of Nursing, Debre Markos University, Debre Markos, Ethiopia.

\section{Appendix}

See Tables 2 and 3.

Table 2 Bivariate analysis of associated factors at level-1 demographic health variables with CS N=17,193

\begin{tabular}{|c|c|c|c|}
\hline Covariates & $\begin{array}{l}\text { CS n (\%) } \\
\text { mean (sd) }\end{array}$ & $\begin{array}{l}\text { All vaginal birth } \mathrm{n}(\%) \\
\text { mean (sd) }\end{array}$ & P-value \\
\hline Religion & & & 0.000 \\
\hline Orthodox and Catholic & $139(54.29)$ & $2279(32.85)$ & \\
\hline Protestant & $42(16.41)$ & $1296(18.68)$ & \\
\hline Muslim & $74(28.90)$ & $3250(46.85)$ & \\
\hline Other & $1(0.39)$ & $112(1.61)$ & \\
\hline Education & & & 0.000 \\
\hline Not educated & $42(16.41)$ & $4317(62.23)$ & \\
\hline Primary & $85(33.20)$ & $1857(26.77)$ & \\
\hline Secondary & $56(21.88)$ & $521(7.51)$ & \\
\hline Higher & $73(28.52)$ & $242(3.49)$ & \\
\hline Birth order & $2.31(1.83)$ & $3.98(2.56)$ & 0.000 \\
\hline Preceding birth interval & $60.51(34.98)$ & $40.95(23.55)$ & 0.000 \\
\hline Multiple pregnancy & & & 0.000 \\
\hline Single & $240(93.75)$ & $6842(98.63)$ & \\
\hline Multiple & $16(6.25)$ & $160(1.37)$ & \\
\hline
\end{tabular}


Table 2 (continued)

\begin{tabular}{|c|c|c|c|}
\hline Covariates & $\begin{array}{l}\text { CS n (\%) } \\
\text { mean (sd) }\end{array}$ & $\begin{array}{l}\text { All vaginal birth } \mathrm{n}(\%) \\
\text { mean (sd) }\end{array}$ & P-value \\
\hline Place of delivery & & & 0.000 \\
\hline Home & $0(0 \%)$ & $1498(64.5 \%)$ & \\
\hline Government's institution & $179(69.9 \%)$ & $2264(32.6 \%)$ & \\
\hline Private Institution & $70(27.3 \%)$ & $125(1.8 \%)$ & \\
\hline NGO Institution & $7(2.7 \%)$ & $54(0.8 \%)$ & \\
\hline ANC & & & 0.000 \\
\hline$\leq 3$ & $61(23.8 \%)$ & $4512(65 \%)$ & \\
\hline$>3$ & $195(76.2 \%)$ & $2425(35 \%)$ & \\
\hline Size of child & & & 0.001 \\
\hline Large & $104(40.6 \%)$ & $2059(29.7 \%)$ & \\
\hline Medium & $94(36.7 \%)$ & $2896(41.7 \%)$ & \\
\hline Small & $58(22.7 \%)$ & $1992(28.6 \%)$ & \\
\hline Party & & & 0.000 \\
\hline 1 & $115(44.9 \%)$ & $1355(19.5 \%)$ & \\
\hline$[2-5]$ & $112(43.8 \%)$ & $2978(42.9 \%)$ & \\
\hline$>5$ & $29(11.3 \%)$ & $2604(37.5 \%)$ & \\
\hline Smoking status & & & 0.719 \\
\hline No & $254(99.22)$ & $6867(98.99)$ & \\
\hline Yes & $2(0.78)$ & $70(1.01)$ & \\
\hline Sex of child & & & 0.328 \\
\hline Male & $140(54.69)$ & $3578(51.58)$ & \\
\hline Female & $116(45.31)$ & $3359(48.42)$ & \\
\hline History of abortion & & & 0.062 \\
\hline No & $225(87.89)$ & $6331(91.26)$ & \\
\hline Yes & $31(12.11)$ & 606 (8.74) & \\
\hline Drugs take for intestinal disease & & & 0.215 \\
\hline No & $232(90.63)$ & $6478(93.38)$ & \\
\hline Yes & $24(9.37)$ & $459(6.62)$ & \\
\hline Anemia & & & 0.001 \\
\hline Sever & $2(0.78)$ & $117(1.69)$ & \\
\hline Moderate & $11(4.30)$ & $659(9.50)$ & \\
\hline Mild & $44(17.19)$ & $1535(22.12)$ & \\
\hline Not anemic & 199 (77.73) & $4626(66.69)$ & \\
\hline Wealth index & & & 0.000 \\
\hline Poorest & $17(6.64)$ & $2411(34.76)$ & \\
\hline Poorer & $12(4.69)$ & $1167(16.82)$ & \\
\hline Middle & $13(5.07)$ & $1015(14.63)$ & \\
\hline Richer & $14(5.47)$ & $903(13.02)$ & \\
\hline Richest & $200(78.13)$ & $1441(20.77)$ & \\
\hline
\end{tabular}


Table 3 Multilevel logistic regression analysis of level-1 and level-2 demographic health factors associated with CS, 2016EDHS

\begin{tabular}{|c|c|c|c|c|}
\hline Covariates & $\begin{array}{l}\text { Model_1 } \\
\text { AOR }(95 \% \mathrm{Cl})\end{array}$ & $\begin{array}{l}\text { Model_2 } \\
\text { AOR }(95 \% \mathrm{Cl})\end{array}$ & $\begin{array}{l}\text { Model_3 } \\
\text { AOR }(95 \% \mathrm{Cl})\end{array}$ & $\begin{array}{l}\text { Model_4 } \\
\text { AOR }(95 \% \mathrm{Cl})\end{array}$ \\
\hline Education level (not educated) & & 1 & & 1 \\
\hline Primary & & $1.01(0.99,1.02)$ & & $1.01(0.99,1.02)$ \\
\hline Secondary & & $1.02(1.00,1.03)$ & & $1.02(1.00,1.03)$ \\
\hline Higher & & $1.10(1.07,1.12)^{*}$ & & $1.09(1.07,1.12)^{*}$ \\
\hline Birth order & & $1.00(1.00,1.00)$ & & $1.00(1.00,1.00)$ \\
\hline Preceding birth interval & & $1.00(1.00,1.00)^{*}$ & & $1.00(1.00 .1 .00)^{*}$ \\
\hline Child is twin (single) & & 1 & & 1 \\
\hline Multiple & & $1.11(1.08,1.15)^{*}$ & & $1.11(1.08,1.15)^{*}$ \\
\hline Place of delivery (home) & & 1 & & \\
\hline Government institution & & $1.04(1.03,1.05)^{*}$ & & $1.04(1.03,1.05)^{*}$ \\
\hline Private Institution & & $1.29(1.26,1.33)^{*}$ & & $1.29(1.25,1.32)^{*}$ \\
\hline NGO Institution & & $1.07(1.03,1.12)^{*}$ & & $1.07(1.02,1.12)^{*}$ \\
\hline \multicolumn{5}{|l|}{ History of abortion (no) } \\
\hline Yes & & $1.01(0.99,1.02)$ & & $1.01(0.99,1.02)$ \\
\hline \multicolumn{5}{|l|}{$\operatorname{ANC}(\leq 3)$} \\
\hline$>3$ & & $1.01(1.00,1.02)$ & & $1.01(1.00,1.02)$ \\
\hline \multicolumn{5}{|l|}{ Size of child (large) } \\
\hline Medium & & $0.99(0.98,0.99)^{*}$ & & $0.99(0.98,1.00)^{*}$ \\
\hline Small & & $0.99(0.98,1.01)$ & & $0.99(0.98,1.01)$ \\
\hline \multicolumn{5}{|l|}{ Parity (1) } \\
\hline$[2-5]$ & & $0.98(0.97,0.99)^{*}$ & & $0.98(0.97,0.99)^{*}$ \\
\hline$>5$ & & $0.98(0.96,1.00)$ & & $0.98(0.96,1.00)$ \\
\hline Anemic status (sever) & & 1 & & 1 \\
\hline Moderate & & $0.99(0.96,1.03)$ & & $0.99(0.96,1.03)$ \\
\hline Mild & & $1.00(0.97,1.03)$ & & $1.00(0.96,1.03)$ \\
\hline Not anemic & & $1.00(0.96,1.03)$ & & $0.99(0.96,1.03)$ \\
\hline Household wealth index (poorest) & & 1 & & 1 \\
\hline Poorer & & $0.99(0.98,1.00)$ & & $0.99(0.98,1.00)$ \\
\hline Middle & & $0.99(0.97,1.00)$ & & $0.99(0.97,0.99)^{*}$ \\
\hline Richer & & $0.98(0.97,0.99)^{*}$ & & $0.98(0.97,0.99)^{*}$ \\
\hline Richest & & $1.01(1.00,1.03)$ & & $1.00(0.98,1.02)$ \\
\hline Residance (Urban) & & & 1 & 1 \\
\hline Rural & & & $0.93(0.91,0.94)^{*}$ & $0.98(0.96,0.99)^{*}$ \\
\hline Region (Tigray) & & & 1 & 1 \\
\hline Afar & & & $0.99(0.97,1.01)$ & $1.01(0.98,1.05)$ \\
\hline Amhara & & & $0.99(0.98,1.02)$ & $1.00(0.99,1.02)$ \\
\hline Oromia & & & $0.99(0.97,1.01)$ & $1.02(1.00,1.03)$ \\
\hline Somali & & & $0.98(0.96,0.99)^{*}$ & $1.01(0.99,1.03)$ \\
\hline Benshangul & & & $0.99(0.97,1.01)$ & $1.00(0.98,1.02)$ \\
\hline SNNP & & & $1.005(0.98,1.02)$ & $1.01(0.99,1.03)$ \\
\hline Gambella & & & $0.98(0.96,0.99)^{*}$ & $1.02(1.01,1.04)^{*}$ \\
\hline Hareri & & & $1.07(1.05,1.09)^{*}$ & $0.98(0.96,0.99)^{*}$ \\
\hline Addis Abeba & & & $1.14(1.11,1.18)^{*}$ & $1.06(1.04,1.09)^{*}$ \\
\hline Dire Dewa & & & $1.03(1.004,1.05)^{*}$ & $1.08(1.06,1.11)^{*}$ \\
\hline Communities variance (se) & $1.064(0.602)$ & $1.001(0.17)$ & $1.038(0.037)$ & $1.002(0.17)$ \\
\hline ICC & $24.44 \%$ & $23.33 \%$ & $23.98 \%$ & $23.35 \%$ \\
\hline PCV & Ref & $5.92 \%$ & $3.7 \%$ & $3.5 \%$ \\
\hline \multicolumn{5}{|l|}{ Model fit } \\
\hline log likelihood & 2169.56 & 2540.081 & 2268.38 & 2559.534 \\
\hline AIC & -4333.119 & -5030.163 & -4510.76 & -5051.068 \\
\hline
\end{tabular}

*Significant at P-value $<0.05$ 
Received: 24 August 2019 Accepted: 3 October 2019

Published online: 06 November 2019

\section{References}

1. Betrán AP, et al. Rates of caesarean section: analysis of global, regional and national estimates. Paediatr Perinat Epidemiol. 2007;21(2):98-113.

2. Mekbib TA, Teferi B. Caesarean section and foetal outcome at Yekatit 12 Hospital, Addis Abeba, Ethiopia, 1987-1992. Ethiop Med J. 1994;32(3):173-9.

3. Bayou YT, et al. Patterns of caesarean-section delivery in Addis Ababa, Ethiopia. Afr J Prim Health Care Fam Med. 2016:8(2):953.

4. Todman D. A history of caesarean section: from ancient world to the modern era. Aust N Z J Obstet Gynaecol. 2007:47(5):357-61.

5. Helal $A$, et al. Rising rates of caesarean delivery at Mansoura University hospital: a reason for concern. Gynecol Obstet. 2013. https://doi. org/10.4172/2161-0932.1000146.

6. Harrison MS, Goldenberg RL. Cesarean section in sub-Saharan Africa. Maternal Health Neonatology and Perinatology. 2016;2(1):6.

7. Adewuyi EO, et al. Cesarean delivery in Nigeria: prevalence and associated factors - a population-based cross-sectional study. BMJ Open. 2019;9(6):e027273.

8. Central Statistical Agency-CSA/Ethiopia and ICF. Ethiopia Demographic and Health Sruvey 2016. Addis Ababa, Ethiopia: CSA and ICF; 2017.

9. Tsega F, et al. Prevalence of cesarean section in urban health facilities and associated factors in Eastern Ethiopia: hospital based cross sectiona study. J Preg Child Health. 2015;2(3):169-73.

10. Wondie AG, et al. Cesarean delivery among women who gave birth in Dessie town hospitals, Northeast Ethiopia. PloS ONE. 2019;14(5):e0216344.

11. Gebremedhin S. Trend and socio-demographic differentials of Caesarean section rate in Addis Ababa, Ethiopia: analysis based on Ethiopia demographic and health surveys data. Reprod Health. 2014;11(1):14.

12. Alemayehu $\mathrm{G}$. outcome of cesarean section and the associated factors at Jugel Hospital, Harari Region, Eastern Ethiopia. 2015, Haramaya University.

13. Gamble JA, Creedy DK. Women's request for a cesarean section: a critique of the literature. Birth. 2000;27(4):256-63.

14. Kamal SM. Preference for institutional delivery and caesarean sections in Bangladesh. J Health Popul Nutr. 2013;31(1):96-109.

15. Wax JR. Maternal request cesarean versus planned spontaneous vaginal delivery: maternal morbidity and short term outcomes. In: Seminars in perinatology. 2006. Elsevier.
16. Gibbons L et al. Inequities in the use of cesarean section deliveries in the world. Am J Obstet Gynecol. 2012;206(4):331.e1-19.

17. Alheshimi SJ, et al. The prevalence of cesarean section in Misan province and it's indicating factors. Indian J Public Health Res Dev. 2019;10(3):425-30

18. Birara M, Gebrehiwot Y. Factors associated with success of vaginal birth after one caesarean section (VBAC) at three teaching hospitals in Addis Ababa, Ethiopia: a case control study. BMC Pregnancy Childbirth. 2013;13(1):31.

19. Ananth CV, et al. The association of placenta previa with history of cesarean delivery and abortion: a metaanalysis. Am J Obstet Gynecol. 1997:177(5):1071-8.

20. Rafiei M, et al. Prevalence, causes, and complications of cesarean delivery in Iran: a systematic review and meta-analysis. Int J Reprod Biomed (Yazd). 2018;16(4):221-34.

21. Teguete I, et al. Determining factors of cesarean delivery trends in developing countries: lessons from point G National Hospital (Bamako-Mali). 2012: p. 161-202.

22. Abebe FE, et al. Factors leading to cesarean section delivery at Felegehiwot referral hospital, Northwest Ethiopia: a retrospective record review. Reprod Health. 2015;13(1):6.

23. Al Rifai RH. Trend of caesarean deliveries in Egypt and its associated factors: evidence from national surveys, 2005-2014. BMC Pregnancy Childbirth. 2017;17(1):417

24. Akki JS, et al. A review of caesarean delivery in Southwest Ethiopia: incidence, indications and outcomes. Afr J Midwifery Women's Health 2015:9(3):106-11.

25. Mekonnen ZA, et al. Multilevel analysis of individual and community leve factors associated with institutional delivery in Ethiopia. BMC Res Notes. 2015;8(1):376

26. Gutema $\mathrm{H}$, Shimye A. Cesarean section and associated factors at mizan aman general hospital, southwest Ethiopia. J Gynecol Obstet. 2014;2(3):37-41.

\section{Publisher's Note}

Springer Nature remains neutral with regard to jurisdictional claims in published maps and institutional affiliations.
Ready to submit your research? Choose BMC and benefit from

- fast, convenient online submission

- thorough peer review by experienced researchers in your field

- rapid publication on acceptance

- support for research data, including large and complex data types

- gold Open Access which fosters wider collaboration and increased citations

- maximum visibility for your research: over 100M website views per year

At BMC, research is always in progress.

Learn more biomedcentral.com/submissions 